\title{
Aproximación a las Églogas del Engaño del novohispano Juan de Cigorondo.
}

\section{Approach to New Spanish Juan de Cigorondo's Églogas del Engaño.}

Esta obra está bajo una Licencia Creative Commons Atribución 4.0 Internacional. DOI: $10.32870 /$ sincronia.axxii.n74.15b18

\author{
Alejandro Arteaga Martínez \\ Universidad Autónoma de la Ciudad de México \\ alejandro.arteaga@uacm.edu.mx \\ (MÉXICO)
}

Recibido: $31 / 07 / 2017$

Revisado: $12 / 03 / 2018$

Aprobado: $12 / 06 / 2018$

\section{RESUMEN}

Juan de Cigorondo (1560-1611), jesuita afincado en Nueva España, compuso su obra teatral Églogas del Engaño probablemente durante la década de 1580. En esta extensa e inconclusa obra alegórica, el dramaturgo aprovecha un tema tradicional para hacer señalamientos sobre la familia, la educación y la corrupción social. Al ser las Églogas una muestra del teatro de colegio, la lectura propagandística de su contenido didáctico y moralizante apunta también hacia un público particular: los miembros del colegio jesuita y los familiares de los estudiantes.

Palabras clave: Teatro de colegio. Teatro alegórico. Compañía de Jesús. Dramaturgia mexicana. Dramaturgia novohispana.

\section{ABSTRACT}

Juan de Cigorondo (1560-1611), a Jesuit based in New Spain, composed his play Églogas del Engaño (Eclogues of Deceit) probably during the 1580s. In this extensive and unfinished allegorical work, the playwright takes advantage of a traditional theme to draw attention to family, education and social corruption. Since the Églogas are a sample of School Theater, the propagandistic reading of its didactic and moralizing content also points to a particular audience: members of the Jesuit College and the students' families. 
Keywords: School Theater. Allegorical Theater. Company of Jesus. Mexican Dramaturgy. New Spain Dramaturgy.

\section{Descripción de la obra}

En el último cuarto del siglo XVI, Juan de Cigorondo (Cádiz, 1560 - Nueva España / México, 1611) desarrolló una intensa labor dentro de la Compañía de Jesús. Cigorondo había migrado al virreinato novohispano en 1568, cuando su padre vino comisionado para investigar lo relacionado con Martín Cortés y su revuelta. Cigorondo ingresó a la Compañía en Nueva España y en su seno desempeñó actividades docentes y administrativas, además de producir una abundante obra poética y dramática que debió esparcirse tras la expulsión de la orden en el siglo XVIII. Este último hecho explicaría el porqué los manuscritos con obra de Cigorondo se conservan en la Biblioteca Nacional de España, la Biblioteca de la Real Academia de la Historia, la Biblioteca de la Hispanic Society of America y en un manuscrito misceláneo de la Biblioteca Nacional de México (Arteaga, 2016).

Cigorondo debió estar en contacto con los círculos intelectuales novohispanos. En sus funciones de profesor y rector de colegios jesuitas en la capital del virreinato y después en otras regiones de este, habrá conocido y establecido vínculos con los literatos del momento. Al menos sabemos que tuvo contacto con Eugenio de Salazar, rector de la Universidad de México entre 1592 y 1593, y poeta discreto. Cigorondo compuso una sextina y un soneto para la Navegación del alma de Salazar (2011) y los términos encomiásticos de ambas piezas quizá son más que solo retóricos, puesto que las inéditas Églogas del Engaño (2015) de Cigorondo comparten el tema de la Navegación: en ambas obras alegóricas, los autores reconstruyeron el desarrollo del hombre desde su nacimiento hasta su madurez. En este devenir, los protagonistas experimentan los peligros del mundo y reconocen la salvación de la virtud gracias a los principios del buen vivir propuestos por el catolicismo.

Las Églogas del Engaño ocupan la parte final del Cartapacio curioso, colección manuscrita de obras teatrales y poéticas de Cigorondo. También son la más extensa pieza bucólica de toda la obra 
cigorondiana conocida: 3683 versos integran ese trabajo que quedó inconcluso. Las otras composiciones bucólicas que conocemos de Cigorondo son un Coloquio a la pastoril de 1058 vv. (Cigorondo, 2012), la Égloga pastoril al nacimiento del niño Jesús de 1509 vv. (Cigorondo, 1979), la Ecloga seu pastorum lusus, quorum subiectum Maria Magdalena est de 1705 vv., y la Égloga del Santísimo Sacramento de $101 \mathrm{vv}$. (Arteaga, 2017a). ${ }^{1}$ Estas églogas, excepto la última, son obras de estructura dramática; la Égloga del Santísimo Sacramento es una composición activa, pero carente de una estructura representable; por su forma, se encuentra más cercana a la bucólica de tradición teocritana.

Las Églogas del Engaño presentan dos letras diferentes, lo que nos hace suponer que el manuscrito 17286 de la Biblioteca Nacional de España, donde se conserva la pieza, es una copia. En el f. 291v de las Églogas se hace referencia al pirata Juan Draque (John Drake) ${ }^{2}$ y, en el f. 293r, al papa Sixto V (1585-1590). Estas dos figuras históricas se ubican en la segunda mitad del siglo XVI. Si consideramos que las noticias del cautiverio y liberación de Drake pudieron circular luego de 1582 y que en 1585 Cigorondo era profesor de retórica y gramática en Puebla (Alonso, 2006, p. li), pensamos factible afirmar que las Églogas datan de la segunda mitad de esa década y que es, quizá, una obra de juventud del dramaturgo novohispano, aunque esta datación sea apenas una hipótesis que deberá demostrarse con mayor evidencia y rigor. $^{3}$

Las Églogas se componen de cuatro bucólicas, cada una con tres églogas, pero el conjunto es una pieza teatral extensa e inconclusa que sigue, en su organización, el Bucolicum carmen de Petrarca, organizado de manera idéntica en bucólicas que contienen églogas. Esta división equivale, en Cigorondo, a una división en actos y escenas. No sorprende la influencia italianizante en esta

\footnotetext{
${ }^{1}$ Sobre la producción bucólica de Cigorondo, puede verse también Arteaga Martínez (2017b).

2 Posiblemente se trata del sobrino o hermano de Francis Drake. En 1582, John Drake perdió el barco a su cargo cuando navegaba en la escuadra de Francis Drake por el Río de la Plata y fue apresado por los charrúas; luego de escapar con algunos sobrevivientes, se entregó a las autoridades españolas de la actual ciudad de Buenos Aires (Childs, 2014, p. 86). ${ }^{3}$ La ficha 860 del Catálogo del antiguo teatro escolar hispánico (Alonso, 2016) consigna los datos siguientes en relación con el lugar y fecha de representación o composición de las Églogas: “Ciudad de México (Nueva España) [...] a principio de un año de año entre 1587 a 1590" (s. v. églogas del engaño), pero no hay indicaciones de las fuentes con las cuales se hace esta aseveración.
} 
extensa obra de la que venimos hablando, pues Cigorondo ya había utilizado el Lusus pastoralis de Andrea Navagero y el propio Bucolicum carmen en su Coloquio a lo pastoril, entre otras fuentes con las cuales desarrolló ahí un proceso intertextual típico del género bucólico, como demostró Alonso Asenjo en su edición del Coloquio. La acción en las Églogas es escasa, pero suficiente para ofrecer un atractivo devenir de los protagonistas en medio de la predominancia de parlamentos extensos y solemnes.

Resulta de interés comparar las Églogas con la Navegación de Salazar. En esta obra, el protagonista puede identificarse con el autor, lo que da al poema una apariencia autobiográfica. Según Jessica C. Locke, las Etimologías de Isidoro de Sevilla son, entre otras fuentes posibles, una con la cual coincide parcialmente la división del poema de Salazar en cuanto a las siete edades del hombre se refiere -infancia, puericia, adolescencia o mocedad, juventud, edad viril o varonil o edad madura, senectud y decrepitud-, aunque Salazar no sigue al pie de la letra los tiempos que abarca cada una según las fuentes clásicas:

Se podría pensar que, respecto a las primeras edades, Salazar siguió a Isidoro: ambos coinciden en que la Infancia "comprehende los siete años primeros de la vida" (Nav. f. 15r); la Puericia, desde los ocho hasta los catorce; y la Adolescencia, desde los quince hasta los veintiocho. Pero a partir de la cuarta edad, hay discrepancias entre Salazar e Isidoro: según aquel, la Juventud termina a los 42 años; según este, a los 50 [...]. La edad que Salazar denomina como "Viril" o "Varonil" podría considerarse como la equivalencia de la que Isidoro llama "aetas senioris, id est, gravitas, quae est declinatio a juventute in senectutem, nondum senectus, sed jam non juventus"; pero mientras que en la Navegación esta edad corre desde los 43 años hasta los 56, en Isidoro, "quae aetas quinquagesimo anno incipiens, septuagesimo terminatur". A partir de esta edad, hay pocos puntos de contacto entre los dos autores. (Locke, 2011, p. 32) 
Salazar elabora esta precisa y particular cronología quizá pensando en su propia persona: habría muerto con 72 o 73 años, año y medio después de elaborar su testamento. ${ }^{4}$ Cigorondo no será tan puntual en los periodos, pero se distingue, como veremos enseguida, al menos la infancia, la puericia y la adolescencia como lapsos de desarrollo de los protagonistas de las Églogas.

\section{La trama de la obra}

Las Églogas del Engaño de Cigorondo parten de un principio temático semejante al de la Navegación de Salazar, aunque desarrollado en una estructura diferente: la reconstrucción de la vida del ser humano en clave bucólica. El poeta afirma esta intención en el Argumento de las Églogas cuando declara que:
Así, de la niñez a la acabada,
perfecta edad del hombre nos iremos,
paso a paso, tejiendo esta enredada
trama lo menos largo que podremos.
Y porque vaya a más sabor labrada,
entre ovejas y cabras la pondremos,
que no sé qué se tiene de dulzura
esto de campo, flores y frescura. (ff. 211v-212r, vv. 17-24) ${ }^{5}$

A diferencia de Salazar, en cuya Navegación la monodia del poeta ocupa prácticamente la totalidad de los cantos (interrumpida por la interpelación de la Sabiduría), Cigorondo entreteje en sus Églogas

\footnotetext{
${ }^{4}$ En relación con esta lazo textual entre la obra y la vida, Locke comenta que el carácter autobiográfico de la Navegación estaría demostrado por la explicitación de la edad de Salazar en el momento en el que compone su poema; en los primeros versos, la voz poética afirma que tiene 70 años (Salazar, 2011, pp. 26-27), lo que correspondería a 1600, año posible de la redacción, según la editora de la Navegación. De ser correcta esta datación, se demostraría que no hay una influencia temática directa de Salazar sobre las Églogas de Cigorondo, sino de Cigorondo hacia Salazar.

${ }^{5}$ La paleografía de las Églogas del Engaño fue realizada por mí y por Ana Lilia Félix Pichardo, estudiante de la Universidad Autónoma de Zacatecas, quien hizo una estancia de investigación conmigo en el 2015 por medio del proyecto XXV Verano de la Investigación Cientifica de la Academia Mexicana de Ciencias. Sobre aquella versión, presento aquí fragmentos de mi edición modernizada de la obra de Cigorondo.
} 
el desarrollo vital de tres protagonistas: Gracilvio, hijo de Tirreno y Tirrena, quien representa al ser humano; el Engaño, hijo de la Malicia y sobrino de la Mentira; y la Virtud, hija de Laboriano y Celia. Sin tener la precisión de Salazar en la distinción de las edades del hombre, Cigorondo deja claro en el Argumento que las Églogas trazan el desarrollo de cada personaje desde su nacimiento hasta la "perfecta edad del hombre". El triángulo dramático establece, además, oposiciones y afinidades que dibujan un mapa conflictivo (adecuado para la representación) en la vida del ser humano:

Nació el hombre del grave y caudaloso

pastor Tirreno, en noche alegre y buena,

al primer parto, en todo venturoso,

que tuvo la cabal, gentil Tirrena.

Mostró ser este parto misterioso:

la blanca luna, antes de tiempo llena.

Ni es sin misterio de Tirreno el nombre, que tierra es y en tierra acaba el hombre.

[...]

Nació también con bendición del cielo, del Trabajo en la rica honrosa estanza, más clara la Virtud que el sol al suelo: joya que, a gotas de sudor, se alcanza para que así tuviese el franco vuelo del hombre do anidase su esperanza, pues sola la Virtud, en hecho y nombre, es la que iguala la altivez del hombre.

Nació también, en ese mismo punto, de la Malicia el burlador Engaño, que no hay un bien a otro bien tan junto que no se mezcle de algún mal el daño. Y este rapaz nació tan puesto a punto 


\author{
en contra el hombre, que excedió el tamaño \\ en fábricas de Error; mas no me admira, \\ que le crió a sus pechos la Mentira. \\ Ved, pues, si hay más en esta humana vida \\ que aquestos tres nacidos como cuento: \\ la Virtud para ser apetecida, \\ y el Hombre para darle en su alma asiento, \\ y el Engaño, carcoma mal sentida, \\ para serles en todo impedimento. (ff. 212r-213r, vv. 25-30, 41-62)
}

De este modo quedan presentados los personajes y establecido el nudo dramático de las Églogas: el ser humano / Gracilvio busca a la Virtud, pero durante esa búsqueda su camino se cruza con el del Engaño, quien hace lo imposible para impedir a aquel el feliz encuentro. La vida del hombre está en una tensión constante entre el bien y el mal desde el nacimiento y hasta su muerte. Cigorondo representará este conflicto construyendo ámbitos particulares de convivencia para Gracilvio y el Engaño (la Virtud es más una referencia discursiva que un personaje escénico a lo largo de la obra), espacios en los cuales se irá moldeando la naturaleza humana: el espacio del trabajo familiar, en el que los padres de los recién nacidos discuten con amigos o vecinos la mejor forma de educar a los hijos, ocupa la primera bucólica. En la segunda, Cigorondo construye un espacio escolar. En la tercera y cuarta bucólicas, Gracilvio y el Engaño dejan el nido familiar y se aventuran al mundo en busca de sus intereses: el primero, tras la Virtud; el segundo, tras Gracilvio. No contamos con la parte final prometida en el Argumento, ese locus amoenus en el que Gracilvio llega a las "riberas de un arroyo manso" donde "vio celebrar las honras del descanso" y reconoce la naturaleza perversa del Engaño para, por último, derrotar a los vicios y alcanzar a la Virtud. Familia, escuela y mundo son, entonces, los tres ámbitos entre los cuales se desarrolla el devenir de la vida del ser humano, con sus obstáculos y éxitos gracias al libre albedrío con que está dotado Gracilvio. Su educación y su conciencia moral son las únicas brújulas que lo orientan en el camino hacia la Virtud. 


\section{La reflexión pedagógica}

La reflexión sobre la crianza de los hijos abre las Églogas. Gracias al triángulo agonal entre los protagonistas, resulta posible para el dramaturgo ofrecer tres visiones sobre la educación temprana de los infantes. La reflexión pedagógica tiene un valor sustancial en este discurso dramático porque el niño es un ciudadano potencial y su salud física y moral es la salud física y moral de la comunidad en la que vive. El contraste entre las diferentes visiones de los padres de Gracilvio, el Engaño y la Virtud sobre qué hacer con ellos para convertirlos en las mejores personas (incluso el Engaño deberá ser bueno en el arte del embuste) resulta útil para el destinatario de las Églogas, pues gracias al contraste entre los intereses de los padres se aprecia lo correcto y lo incorrecto de los diferentes estilos de crianza. El hecho de que haya un personaje femenino, la Virtud, extiende el alcance de la reflexión sobre la educación de la mujer, aunque sea de manera breve en esta primera sección de la obra.

Las formas de crianza de los tres recién nacidos tienen un sustento moral que los padres detallan en conversaciones casuales con sus amigos. Hay una representación específica de qué es ser un buen o un mal padre en relación con los hijos propios. Las conversaciones de los padres con sus conocidos sobre estos temas nos remite al diálogo renacentista como medio de enseñanza: las preguntas y las respuestas de los participantes permiten exponer los argumentos y conclusiones sobre este asunto de la crianza. Esta incorporación de una forma dialogal impide, por su naturaleza exclusivamente discursiva, un desarrollo teatral pleno; se trata de escenas más bien estáticas que requieren únicamente la atención del espectador para entender el problema ético propuesto en el discurso dramático. En consecuencia, la trama tiene un desarrollo casi nulo en esta primera parte de las Églogas. Como ejemplo de esta inicial reflexión pedagógica crítica, señalaremos que la discusión sobre la paternidad tiene tres ejes: el labrador Tirreno piensa de manera práctica, pero responsable, sobre qué deberá hacerse para que su Gracilvio se convierta en un buen hombre; la Malicia, madre del Engaño, no hace caso del recién nacido y lo ha dejado a cargo de alguien más; 
Laboriano, alegoría del trabajo, se preocupa por la responsabilidad que implica criar a una hija tan bella como la Virtud: hay que estar, dice Laboriano, más atentos a ella, porque será objeto de múltiples afectos impuros.

Tirreno dialoga con Carpino sobre su primogénito. La fragilidad de Gracilvio y la naturaleza de su concepción preocupan al padre tanto como la salud delicada de la madre. Tirreno, atento a estas preocupaciones, planea buscar a una nodriza que alimente a su hijo al menos por día. Carpino replica que es mala idea, pues no hay certeza de las buenas costumbres de esa otra mujer y a través de la leche el niño, en ese primer encuentro con el alimento del mundo, puede corromperse; por esto aconseja que Tirrena haga un esfuerzo para amamantar a su hijo:

Si es por tan poco, Tirreno,

pásese como pudiere,

mas haz, en cuanto en ti fuere,

que no sea el pecho ajeno;

mame alguna cabritilla,

la más mansa y regalada,

y con miel, al sol curada,

hazle endulcen la boquilla.

Cuanto más, que me sospecho,

que aun no habría inconveniente

si flaca, como se siente,

le diese Tirrena el pecho.

Que no, Pastor, no es flaqueza

lo que nos daña e impide

lo que ahí, en su fuero, pide

la madre naturaleza. (f. 221r, vv. 385-400)

Tirreno acepta el consejo de su amigo Carpino y elabora una crítica contra las mujeres que se niegan a dar el pecho a sus hijos, acusándolas más bien de vanidosas y melindrosas, puesto que ni 
su salud se merma por alimentar a sus hijos ni su cuerpo se estropea por esta actividad natural; e incluso, añade Tirreno, resulta una práctica nociva la utilización de nodrizas cuando las madres solo buscan con ello tiempo para atender a sus mascotas y no a los recién nacidos. Finalmente, Tirreno señala una consecuencia fatal para el ejercicio de la autoridad materna sobre los hijos:

Y apurada la verdad

de hierro tan manifiesto,

hay más de melindre en esto

que no de necesidad;

pues hallarás quién despeche

de su regazo los hijos

y a mil otras sabandijas

las acaricie y dé leche.

[...]

Téngalos por excusados

la madre si, ya crecidos,

los hallare desabridos,

ariscos y despegados. (ff. 222rv, vv. 441-448; f. 223v, vv. 485-488)

La preocupación de Tirreno y Carpino por el primer alimento que pruebe el primogénito tiene su origen en la preocupación del cuerpo como recipiente para el alma: lo que dañe el cuerpo, dañará el alma. Este perjuicio es más preocupante si se consideran sus repercusiones en el tejido familiar, como el desapego que tendrán los hijos a la madre, quien es un vínculo fundamental para el desarrollo de valores religiosos y cívicos.

La crianza de la Virtud plantea preocupaciones relacionadas con el sexo de la criatura. Laboriano lo explica así:

Eso mismo, Tigrenio, me ha movido

a ser de mi labor más cudicioso,

sin dar al tiempo un átomo perdido. 


\author{
Parto de hija siempre fue cargoso, \\ pues pide mayor guarda, nuevo apero \\ y padre que la dote, caudaloso" (ff. 237rv, vv. 1045-1050).
}

Tigrenio replica que esta niña es la Virtud, lo que hace una diferencia sustancial en el trato que ha de dársele y alivia, con mucho margen, las preocupaciones de Laboriano en relación con las que otros padres sobrellevan en la crianza de sus hijas; a Laboriano nada de debería preocuparle ahora. Este hace entonces un elogio del trabajo y del uso adecuado del tiempo de ocio, así como del valor que conserva todo lo que se alcanza con esfuerzo y sorteando dificultades:

Si proveíste al bien de tus ganados,

si acudiste al rigor de tu consejo,

si diste ya una vuelta a tus sembrados,

busca de tus amigos el más viejo

y con él trata dulce, afablemente

de lo que la ocasión diere aparejo.

Preguntarasle el tiempo conveniente

del tusquilar y cómo habrá de untarse

la roña en la ovejuela maldoliente;

qué modo habrá en que venga a variarse,

del corderillo, la delgada lana

o el novillo cerrero a domeñarse;

la forma del cayado, la lozana

traza del buen mastín o si quebranta

el rocío a las cabras de mañana.

Y entrándote en tus guertos, poda o planta

o ponte a ver la flor gallarda, hermosa,

cómo sobre el capullo se levanta;

y allí verás la ardiente, suave rosa: 
que ver que, en su defensa, tiene espinas

la hacen en mi estima más preciosa. (ff. 240rv, vv. 1150-1170)

En contraste con estas dos actitudes paternas -el trabajo constante de Laboriano para procurar el bienestar de la Virtud y la preocupación de Tirreno por la adecuada nutrición del niño Gracilvio-, el caso del Engaño y la Malicia, su madre, ofrece un paradigma de la desatención materna, que ya había perfilado negativamente Carpino y que combina ahora una serie de donaciones malévolas para el pequeño Engaño. La Malicia cuenta los acontecimientos tras su parto a la Mentira, su hermana, en medio del bosque donde la primera se encuentra cazando horas después de haber dado a luz:

¡Reíme del alboroto hecho por un rapacejo!

Torné a entrar y, tras mí, el viejo

Carón, mal peinado y roto,

rendido a un bastón de acejo;

y díjome, tremulento,

sin hacerme más caricia

ni otro comedimiento

al entrar del aposento:

“¿Dizque parimos, Malicia?”

Tras d'él, sin el arco fuerte,

entró la Parca fingida,

que el Engaño, de más suerte,

es el que hace la muerte

en el cambio de la vida.

[...]

Esas dos [Venus y Diana] y el cazador,

hijuelo vendado, exento, 
que no es engaño menor

vendérsenos, por amor,

lo que es aborrecimiento.

Y aún los otros dos vinieron

de quien yo más caso hago,

que en los brazos recibieron

al niño y me le envolvieron:

la Lisonja y el Halago.

Todos, al fin, esperando,

riose el niño en naciendo,

que ese es un engaño blando:

que, al nacer, nace riendo

y, al cabo, mata llorando. (ff. 231rv-232r, vv. 792-806, 812-826)

A diferencia de la Virtud, que fue arropada por seres angélicos al nacer, y de Gracilvio, que acapara la atención de Tirreno, la Malicia deja al Engaño "mamando [...] / a pechos de una raposa" (f. 233r, vv. 885-886). Además de este hecho de sentido ambiguo, el Engaño fue apadrinado apadrinado por seres de la oscuridad que huyen al salir el sol, no sin antes desear para él el máximo éxito en la realización de sus futuras maldades. De este modo, el Engaño de las Églogas es la suma de múltiples males, entre ellos el amor malsano que conduce a la muerte; ${ }^{6}$ y es capaz de infligir grandes daños gracias a la Lisonja y el Halago, que exacerban la vanidad del propio Engaño y este, con ayuda de aquellos, la soberbia del ser humano. Tanto Gracilvio como el Engaño, por lo tanto, son el reflejo de sus padres y de las prácticas familiares: los desvelos de los progenitores o su desidia repercuten en la conformación de los valores de los futuros ciudadanos que se gestan al amparo del hogar.

\footnotetext{
${ }^{6}$ La "Parca fingida" remite al número 155 de los Emblemata de Alciato, donde se cuenta cómo el Amor y la Muerte confundieron sus armas una vez, y la Muerte enamoraba y el Amor asesinaba.
} 


\section{La reflexión sobre la escuela}

Durante la infancia, la primera etapa del ser humano según Salazar, los padres se enfrentan a las incógnitas de qué hacer para orientar la vida de sus hijos. Al seguir el consejo de los buenos amigos y las convicciones propias, algunos padres encauzan por la senda del bien a las criaturas o no lo hacen. Con intención o sin ella, los pequeños que carecen de la atención de los padres corren el riesgo de padecer graves daños en el futuro. La familia es el núcleo en el que se cimientan los principios regulares de la convivencia y que aseguran la salvación o la condenación del alma, pero no resulta suficiente para lograr la plena inserción del niño en la sociedad.

A lo largo de la puericia, ese periodo que va de los ocho a los catorce años, el niño tiene la oportunidad de educarse por primera vez fuera de casa, en la escuela. Así es como Cigorondo desarrolla la segunda bucólica de sus Églogas del Engaño: los infantes han crecido, Gracilvio, el hijo de Tirreno, es un pastorcito de buenos modales y acomedido con sus mayores; Engaño, en cambio, es un perezoso; de la Virtud sabremos algo porque otros hacen referencias sobre ella, pero el personaje se desdibuja conforme avanza la trama de las Églogas. Tirreno reflexiona sobre qué debe ser la educación y cómo el maestro; encomienda a su hijo a la dirección de Ursapio, quien tiene fama de ser maestro justo y de enseñar tanto conocimiento como principios. Al mismo tiempo, Malicia lleva a Engaño a la escuela y pide a Ursapio que tenga en cuenta que las travesuras del niño son las propias de su edad y no ameritan reprensión. En la escuela, Engaño convence a sus compañeros de jugar en cuanto el maestro se ausenta y les sugiere mentir si son descubiertos. El maestro se encuentra con el desorden y, tras interrogar a los niños, se da cuenta de que el Engaño instigó a todos y es responsable de lo ocurrido, por lo que lo castiga.

La escuela es un tema típico del teatro jesuita novohispano que ha llegado a nosotros y favorito de Cigorondo, en particular. De Cigorondo conocemos, por ejemplo, la Tragedia del Ocio, que aborda precisamente el tema escolar. Ahí se pregunta el dramaturgo por qué le cuesta aceptar el saber al joven, si intervienen fuerzas malignas en la desidia del estudiante, qué deben o pueden 
hacer el padre y el maestro para remediar la pereza del hijo, que pone en peligro tanto la fama como el alma del estudiante flojo. Pero el tema de la escuela y del estudiante viene de los orígenes del teatro escolar jesuita. Un testimonio antiguo está en el códice 114 de la biblioteca de Mesina: en la obra Adolescens poenitens, el Espíritu del Mal envenena a Carino, Lucilo y Ergasto con el filtro de la rebelión. Carino huye de la casa paterna con la intención de embarcarse y recorrer el mundo con sus amigos, guiados por un demonio disfrazado como hombre de mundo. El desconsolado padre, angustiado por el destino del hijo desobediente, se confía al pedagogo Meliso. Cuando los jóvenes entran a una capilla dedicada a la Virgen para pedir protección durante el viaje, un ángel arroja al guía demoniaco. Este milagro revela a los jóvenes las terribles consecuencias de su intento y, finalmente, padres e hijos, maestro y estudiantes se reconcilian (Soldati, 1908, p. 104). De modo que temáticamente, las Églogas del Engaño se vinculan con una tradición didáctica desarrollada en el seno de la Compañía de Jesús.

De nueva cuenta, los contrastes entre los intereses de los padres en las Églogas del Engaño de Cigorondo hacen evidentes las prácticas positivas y negativas en la educación de los hijos. Tirreno considera importante que el maestro sea una figura de autoridad cuyo comportamiento, sobre todo, sirva de modelo de conducta y, además, sepa transmitir el conocimiento:

Por eso convendría haber cuidado que, en la villa, la escuela no se diese sino a maestro tal calificado.

Y si cual debe ser no le tuviese, tendría por menor inconveniente que no leyese el niño ni escribiese. Aunque el maestro no fuese preminente en lengua y pluma, si en virtud sobrase podríase llevar más fácilmente.

Mas si en esto una mínima faltase, ¿en qué tanto, Carpino, estimarías 
lo que a nuestros hijuelos enseñase?

[...]

Si en el maestro no hay prudencia y celo

del bien del niño, y un ejemplo en vida

más limpio y casto que el luciente cielo;

si no tiene la lengua corregida

y en sus intentos el debido peso

y a la labor la ociosidad rendida,

¿qué mucho crezca el niño en ser travieso,

de mal humor, de altivo sobrecejo,

de estrechas sienes, de enjugado seso? (ff. 259v-250r, vv. 1537-1548; f. 250v, vv. 15641572)

Las consecuencias de un mal maestro marcan al niño que se vuelve travieso, malhumorado, altivo y, encima, con un ingenio nada desarrollado. Estos y otros resultados de una educación laxa (tampoco se aprenderán los conocimientos ni los principios necesarios para la inserción social, por ejemplo) que derivan de la elección incorrecta de maestro recuerdan los que afectan al niño cuya madre delegaba su primera alimentación a otra persona y que crecería desapegado de la familia con las implicaciones derivadas de ese descuido inicial. La escuela ofrece, por lo tanto, otro tipo de alimento para el alma y el intelecto. Por las razones expuestas, Tirreno elige a un maestro en particular:

De Ursapio me contenta la manera

que tiene en enseñar y es hombre cano,

de aspecto grave, de prudencia entera.

No deja los muchachos de la mano,

que la asistencia en ellos es el punto

más importante, más astuto y sano (ff. 250v-251r, vv. 1579-1584). 
El hombre culto, experimentado en la vida y atento al bienestar de los niños resulta la elección lógica de Tirreno para su hijo Gracilvio. En contraste con este padre preocupado por la educación formal de su hijo, la Malicia considera la educación como una carga que debe despachar de cualquier manera; el mínimo esfuerzo que hace para poner al Engaño en la escuela le parece suficiente:

Tiempo es ya, mi dulce Engaño, de que salgáis de mantillas y deis la muestra del paño.

Comprado os he dos cartillas, bastaranos para un año.

No esperéis de mí otra renta, ni os diera más vuestra abuela, que harto hace a mi cuenta la que, por Dios, se sustenta en poner hijo a la escuela. Y esto no lo despreciéis, que no será poca suma, si daros maña sabéis, la que tras niño ganéis en el mundo por la pluma. (ff. 254v-255r, vv. 1725-1739)

Corresponde al Engaño aprovechar lo mejor del año de estudios que le ofrece su madre, sin esperar ningún esfuerzo más de ella. Como si esta despreocupación materna no dañara lo suficiente al pequeño (aunque al final, cualquier defecto incrementará la maldad del Engaño), la Malicia y la Mentira acompañan a su pequeño a la escuela por considerar severa la disciplina escolar y, para que no se maltrate ni física ni emocionalmente al Engaño, ambas mujeres hablan con Ursapio para indicarle los modos correctos que, a juicio de ellas, deben seguirse en la escuela para tratar al niño:

$$
\text { Malicia Por la fama que de vos }
$$


hemos tenido, las dos,

que sabréis somos hermanas,

nos movimos a os traer

este niño de quien, fío,

dará poco en qué entender.

Deseo sepa leer,

que es único hijo mío.

Viene tosco y mal polido,

serrano en traje y palabras,

como entre cabras nacido,

lo más del tiempo perdido,

criado, al fin, entre cabras.

[...]

Mentira Así os ruego yo se haga

y si, como niño, enojos

diere, yo daré la paga

tal que a todos satisfaga,

que es la lumbre de mis ojos.

Malicia No querría se le diese

ni lo que es un papirote

porque, si posible fuese,

d'ese el regalo hiciese

más en él, que no el azote.

Mentira ¡Ay, Dios, que es delicadillo

y no tendrían razón

en lastimarle al chiquillo

y más que nunca el bobillo

supo qué es un bofetón! (ff. 258rv, vv. 1862-1874, 1880-1894) 
Malicia queda representada como una madre cuya sobreprotección causa a su hijo más daño que beneficio. Esta nociva forma de buscar que la escuela se amolde a las necesidades del Engaño no es inocua y contribuye a la malacrianza del pequeño. En el juego de contrastes que se construye en las Églogas, esta actitud de los padres y las madres hacia la disciplina escolar también es analizada. Tirreno, al contrario de la Malicia y la Mentira, da total autoridad al maestro Ursapio para corregir con severidad los errores y la mala conducta de Gracilvio; con ello pretende prevenir que tales vicios queden grabados en el carácter del muchacho y lo dañen socialmente en el futuro:

Pues no, pastor, no quiera el franco cielo

que vaya así. El día que azotares

a mi Gracilvio alabaré tu celo:

corte al punto el rigor lo que hallares

de avieso en él, que en tanto el bien se estima

cuanto menos el mal disimulares;

en sus burlas me mira a quién se arrima

con más estrecho amor que, aunque pequeña,

mancha puede tomar que se le imprima;

mentira no la diga ni por seña,

ni en libro ocioso le permitas lea,

que allí del fuego suele estar la leña;

sombra o figura, amigo, aunque ella sea

del semicapro dios, si está desnuda

harás que de sus ojos no la vea.

Yo tendré cuenta que a su tiempo acuda

sin faltar punto y, de sus muestras, fío

que hará la razón si no se muda. (ff. 253rv, vv. 1663-1680)

Son dos las consideraciones de Cigorondo sobre la relación de la familia con la escuela. Por un lado, la familia desempeña un papel importante en la formación del niño, pues desarrolla buenos hábitos 
en el pequeño como levantarse temprano -“Yo tendré cuenta que a su tiempo acuda / sin faltar punto [...]", dice Tirreno- y ser diligente. En la escuela, esos hábitos sirven para el desarrollo del intelecto: si el niño no es puntual ni diligente, no hay garantía de que en la escuela sea un buen estudiante ni de que se desarrolle ahí su virtud. Por otra parte, Cigorondo critica el papel de la madre frente al del padre: ella suele considerar la fragilidad del hijo y, de este modo, corrompe el carácter del pequeño, incluso si es capaz de llevarlo a la escuela con buena voluntad; el padre, por el contrario, es consciente de la calidad social del hijo como futuro ciudadano y prefiere que aprenda en la escuela que todas sus acciones tienen consecuencias. En este sentido, la cuestión de género parece tener importancia e incidir en la reflexión sobre la educación que, dado el contexto de la obra, tiene a su cargo y ofrece la Compañía de Jesús. Como señalamos en otro trabajo, en la Imago primi saeculi, un libro conmemorativo del primer centenario de vida de la orden jesuita, uno de los emblemas repudia la influencia materna en la educación de los hijos que atienden los maestros jesuitas (Arteaga, 2015, p. 58). Cigorondo sin duda estaba de acuerdo con esta consideración.

\section{La reflexión sobre la vida laboral}

La adolescencia, etapa que va de los 14 a los 28 años, según Salazar, es el periodo de inserción al mundo de los jóvenes con la consecuente aceptación de responsabilidades laborales y maritales. Siguiendo el desarrollo de sus personajes, Cigorondo propone dos nuevos núcleos temáticos en la tercera y cuarta bucólicas: las nupcias entre Gracilvio y la Virtud, y la búsqueda de la subsistencia por cuenta propia de Gracilvio y del Engaño. Sobre las nupcias, Laboriano hace la propuesta a Tirreno en términos claros y razonables al inicio de la tercera bucólica:

Ya tu Gracilvio llega,

de juventud, al tiempo más lozano do el tierno fruto, en flores, aparece.

Agora está en tu mano

hacer del pecho generosa entrega 
en lo que, contra el tiempo, permanece.

Mi noble hijuela [la Virtud] crece

y a mí es forzoso hacer largo camino;

dicho te he que hallo, por su estrella

y próspero destino,

ser tu hijuelo el digno esposo d'ella.

Disimulé algún tanto

cuando, al entrar del huerto, me trataste

d'esto que digo, hasta calar tu pecho;

en ti me retrataste,

de tu Gracilvio, el natural y cuánto

estabas de sus obras satisfecho.

Todo eso es de provecho,

mas la Virtud, en la labor nacida,

al que vivir en su natío quiere,

no se dará aburrida

sino al que, en su sudor, la mereciere. (ff. 271v-272r, vv. 2397-2418)

Como no podía ser de otra manera, el buen Gracilvio se enamora en cuanto conoce a la Virtud. A partir de ese primer encuentro en la casa de Laboriano, el hijo de Tirreno se decide a permanecer fiel a sus sentimientos por la Virtud; sin embargo, al enterarse de que esta se marcha con Laboriano, duda en seguirla si no tiene primero el consentimiento de sus padres. Gracilvio superará cualquier otro obstáculo una vez que tenga la autorización de Tirreno, como explica a su amigo Recelo:

Dícenme que ausentalla el padre intenta, porque él también se ausenta y no se sabe a dónde, que es cual ave Laboriano que, con cada verano, el nido muda. 
Y estoy, amigo, en duda si pidiese

a mi padre quisiese permitirme

en su busca partirme. Yo te juro

que no hay lugar tan duro, inhabitable

o por el intratable rayo ardiente

del sol en la caliente, seca Libia;

o por la grave, fría, amontonada

nieve, si allí llevada fuese, acaso,

que me cerrase el paso a no seguilla. (f. 276v, vv. 2593-2605)

Con la venia de Tirreno, Gracilvio dispone su partida. La despedida entre el padre y el hijo arroja luz sobre la concepción cigorondiana de las relaciones familiares sanas: llegado el momento de la separación del hijo que busca su desarrollo individual, el buen padre no se opone a esta expresión de libertad, sino que se ofrece como apoyo en la búsqueda de la felicidad de aquel. A pesar de la pobreza familiar, el buen padre obsequia al hijo que parte una variedad de objetos que representan valores máximos. De esta manera es como Tirreno dota a Gracilvio con prendas de utilidad, pero con un valor simbólico que le indica a su hijo:

Hijo, para la jornada

no sé qué daros de apero,

que alhajas de un ganadero

suelen valer poco o nada.

Que a mí, allá en la edad pasada,

diéronme, por gran favor,

puesto en el rostro el sudor

y en la mano una azada.

Con todo, os traigo de mío

un gabán de armiño y grana,

mezcla por donde se gana 
pureza con señorío.

Que aunque el justo da de suyo

a la profana alegría

peso al triste, en demasía,

quiebra las alas al brío.

Y porque llevéis calzados

los pies al camino incierto,

abarcas de animal muerto

os traigo y lazos doblados

porque, en pasos alentados,

no halléis el daño abscondido,

ni peligre el pie herido

contra afectos mal domados.

Y porque es justo veléis,

lleváis en este zurrón

yesca, piedra y eslabón

de do la lumbre saquéis;

que vez habrá que os halléis

del frío encogido o ciego

y habréis menester el fuego

que os dé luz, y calentéis.

También os traigo un cayado

que, en ser de acebo, le estimo

que os podrá servir de arrimo

cuando os hallardis cansado;

que en camino poco usado

habrá, de fuerza, aspereza

$y$, si os faltase firmeza,

perderíades lo andado. 


\author{
Y lo que es de más valor: \\ este espejo, y no de acero, \\ mas retrato verdadero \\ de la Virtud, vuestro amor; \\ mirad bien en él, pastor, \\ que hay quien tenga por oficio \\ vender por virtud el vicio; \\ no deis vos en este error. (ff. 280v-281v, vv. 2738-2785)
}

Abrigo, calzado, un cayado, un zurrón con herramientas para hacer fuego y la imagen emblemática de la Virtud son las prendas que regala Tirreno a Gracilvio con la esperanza de que no se pierda en el camino. Las exhortaciones para ser humilde, las advertencias sobre los dañinos peligros del mundo y la invariable fatiga al enfrentar los obstáculos cotidianos son la lectura simbólica de las prendas que da el padre al hijo sin engañarlo sobre las asperezas de la vida. Y aún más: Tirreno ofrece a Gracilvio la compañía de dos personajes cuya sabiduría será de auxilio para el hijo que se marcha en busca de su propio bienestar: el Cuidado y el Recelo (f. 282r, vv. 2802-2817), en cuya compañía y revestido con las prendas paternas Gracilvio empieza su camino en seguimiento de Laboriano y de su amada Virtud. Por su parte, en la bucólica cuarta, al enterarse de la partida de Gracilvio, la Malicia insta al Engaño a partir también en pos del hijo del pastor con la esperanza de que demuestre de una vez por todas cuán capaz es para cometer sus perfidias. De nueva cuenta, Cigorondo contrasta las relaciones filiales, aunque ahora existe un tono cómico típico de las caracterizaciones de los personajes malignos. El diálogo inicial de esta última bucólica de las Églogas del Engaño resulta gracioso por la dependencia anormal que la Malicia y el Engaño reconocen que hay entre ellos, y los rumores y burlas que tal relación provoca en la gente que los conoce:

Malicia Hijo, ya vuestra edad pasa de punto y os sobra el brío para que os estéis, baldío, 


\author{
comiéndome el pan en casa. \\ Que aunque os ven algo mudado, \\ mi hijuelo, sois el Engaño \\ no distinto del pasado, \\ que no es mucho que en un año \\ os hayáis algo trocado. \\ Engaño Madre, si hay algo en que acuda, \\ mandadme a vuestro contento; \\ que me llaman ya, y me afrento, \\ lechoncillo de viuda. (f. 293r, vv. 2834-2846)
}

Las advertencias de la Malicia y la Mentira para el Engaño que se marcha en busca de fortuna y tras Gracilvio tienen un sabor bastante agrio en esta parte de las Églogas. Quizá el enfoque sobre la vida civil, la cual ofrece un amplio terreno para ejercer la crítica, resulta demasiado preciso y, por ello, el tono satírico de la primera égloga de la última bucólica de las Églogas desvanece la comicidad incipiente de la sección. El inicio de la sátira puede ubicarse en el momento cuando la Malicia ofrece a su hijo las pocas prendas que ella posee, como hizo Tirreno con Gracilvio; pero a diferencia de estos, no resulta claro si aquella da algo al Engaño o solo le indica qué oficio debe desempeñar para ganarse la vida: "Tomad, pues, entrañas mías, / la herencia del vizcaíno: / papel, pluma, escribanías; / y, con tanto, ialto!, al camino, / que no hay otras alquerías" (f. 283v, vv. 2865-2869). A partir de esta interlocución, la Malicia y la Mentira se turnan para hacer las advertencias contra el mundo, que son finalmente señalamientos del basto terreno donde el Engaño puede medrar. Resulta de particular interés que la sátira crezca en relación con el mundo administrativo de España y Nueva España, porque Cigorondo hace decir al Engaño que le interesa ser aconsejado sobre qué hacer si Gracilvio decidiera irse al virreinato. La recomendación de la Mentira es precisa: ir a Sevilla y aprovechar la corrupción portuaria. Enseguida, la Malicia y la Mentira añaden varias oportunidades 
que el Engaño podría aprovechar, con paciencia, para viajar de manera ilegal al virreinato novohispano y continuar su persecución del ser humano representado por Gracilvio:

Malicia Y, hijo, aunque algunos años

gastéis en eso no os duela,

que os servirán por escuela

después, en Indias, de engaños.

Tendréis el pulso tomado

a las cosas en que pica,

de interés, lo más delgado,

cual médico que platica

después de ser graduado.

Que esto de contrataciones

(iy más que anda el mar revuelto!),

para el mozo astuto y suelto

es minero de ocasiones.

Pues nunca falta una nave

que, de aquí o de allí, se escapa

o embargo en pella más grave:

la voz del rey es la capa

y el ladrón, quien Dios se sabe.

Mentira Y cuando esto no, paciencia,

que gente vendrá a Sevilla

que, jugada la haciendilla

o por alguna dolencia

o porque el mar no la asombre,

estén en volverse prestos;

donde os es fácil, a un hombre,

comprar la licencia d'estos 
por poco y mudarse el nombre.

$Y$ esto hecho sin ruido,

buscaréis dos, tres testigos

que, interesados o amigos,

juren sois el contenido;

que muy de antiguo lo han

mudar nombre al embarcarse

los más que a las Indias van,

donde el 'Don' suele pegarse

o el 'Manrique' o el 'Guzmán'. (ff. 284v-285v, vv. 2906-2941)

Estos consejos de la Malicia y de la Mentira configuran una crítica contra la corrupción administrativa que controla el paso a Nueva España. Luego de que el Engaño se haga escribiente, entrará de lleno en la ajetreada vida mundana. La migración a Nueva España podría hacerse aprovechando las "palancas" que hubiera hecho en los muelles o falseando su identidad, como suele hacerse de manera frecuente en estos casos (recordemos que, durante el siglo XVI, empezó a controlarse la migración española hacia el continente americano). En Nueva España podría seguir el camino de Veracruz y Puebla para llegar a la capital novohispana. Sobre Puebla, donde Cigorondo fue profesor, dice la Mentira:

Sobrino, allá habrá parientes

$y$, cuando no, la hermandad

de los convalecientes

viéndoos pobre, en caridad

os pasarán a otras gentes.

Pero aquí sólo os requiero

que, si por la Puebla fuerdes,

deis allí en cuanto quisierdes,

mas no deis en tabernero; 
que, en más de lo que se fía,

seréis ladrón todo el año,

pechero lo más del día:

ino es tanto el Engaño

cuanto la bellaquería! (f. 287r, vv. 2991-3004)

El carácter vicioso de los poblanos (alcohólicos, buenos para pedir y malos para pagar) abre la veta satírica sobre la corrupción social novohispana. En la capital, la vida será todavía más complicada para Engaño, porque los leguleyos que pululan por todas partes dificultan hacer peor las cosas; algo similar ocurre en el mercado, donde las trampas de los comerciantes son tan frecuentes que la presencia del Engaño parecería innecesaria. Pero el Engaño no debe cejar y podría elegir entre los ámbitos jurídicos o mercantiles de su preferencia porque ahí, pese a la competencia, es más fácil que encuentre oportunidad de probar su capacidad de engañar. Si opta por una escribanía, por ejemplo, tendrá la oportunidad de enriquecerse pronto:

Pondréis, amigo, los labios

donde hubiere menos ley

y más altivos resabios

que, donde faltare el rey,

no es mucho sobren agravios.

Dad en la Caja Real,

que hay montón y no se siente,

y más si sois escribiente

cuerdo de algún oficial.

Una pluma a vuestro modo

y el sutil cuchillo a tiempo

os dará el dinero a rodo

que, después, es pasatiempo

verlo en maraña de todo. (ff. 288v-289r, vv. 3054-3067) 
El fraude como modo de vida en la capital de Nueva España facilitará la estancia del Engaño en el virreinato y le permitirá acechar no solo a Gracilvio, sino a la humanidad entera. Hay otros oficios igualmente beneficiosos para el medro del Engaño, como el de médico, el de religioso, y lugares donde puede hacer de las suyas como el convento; pero será entre los corros de mujeres donde cree sacar lo mejor de sí, o eso supone hasta que la Malicia lo pone en guardia contra la mujer novohispana: “Que, hijo, su ingenio vuela / por términos tan extraños / que, si se diesen a engaños, / podrían poner escuela" (f. 294r, vv. 3270-3278).

La segunda égloga de la cuarta bucólica (y última parte de las Églogas de Cigorondo) dispone el encuentro del Engaño con Gracilvio. El primero, asustado en la soledad de un bosque, cuenta con la ayuda del Miedo para robar la imagen de la Virtud que Gracilvio lleva consigo. El segundo, cansado del viaje, duerme y ofrecerá entonces la ocasión para que ocurra el hurto. Las Églogas del Engaño concluyen en este punto y no ofrecen la tercera égloga, que contendría el desenlace prometido en el Argumento de la obra, el cual debería ser la revelación del Engaño como un ser nocivo para el ser humano y la presentación de Gracilvio como vencedor de todos los vicios comandados por su enemigo. Sin embargo, a pesar de esta carencia, las Églogas de Cigorondo nos dejan apreciar hacia dónde se dirigía la trama del dramaturgo: hacia un desenlace moralizante que demostraría la dificultad del bien obrar, pero también la generosa recompensa que recibiría quien, como Gracilvio, se decidió a caminar por el mundo para alcanzar a la Virtud. Esa última parte debería tener un mayor desarrollo escénico, ya que Gracilvio habría de luchar contra el Engaño para recuperar la imagen robada y asimismo confrontarse con los aliados de su enemigo. ${ }^{7}$

\footnotetext{
7 Un rasgo estilístico de la dramaturgia cigorondiana son los combates escenificados con que cierran obras como la Comedia a la gloriosa Magdalena y la Ecloga seu pastorum lusus.
} 


\section{Conclusiones}

Las Églogas del Engaño son una biografía alegórica de la vida del ser humano, aquí representado por el personaje de Gracilvio. La alegoría de la vida humana es un tema tradicional y vigente en la segunda mitad del siglo XVI, como demuestra Eugenio de Salazar al componer su Navegación del alma. Cigorondo enmarca sus Églogas en la tradición pastoril y con ello enriquece el tema alegórico al darle una funcionalidad dramática, más que un rigor cronológico al desarrollo, como hiciera Salazar. En este sentido, Gracilvio está acompañado por el Engaño, el oponente de sus buenas acciones. La planeación dramatúrgica del jesuita contiene una carga ideológica prototípica del teatro escolar novohispano: promover valores católicos. Con esta intención propagandística es que la trama de las Églogas sirve también para cuestionar la familia, la educación, el papel de los padres y las madres en esta importante labor de crianza, así como para señalar algunos hechos sobre la corrupción social del mundo.

Las reflexiones que se ofrecen desde el escenario convergen en una intensa sátira de la vida de la corte y, en general, de la vida administrativa del imperio español hacia el final de la obra. La lectura que se puede hacer de ese pasaje satírico obliga a consideraciones morales: lo correcto y lo incorrecto, lo justo y lo injusto, lo cual se logra mediante la comparación entre las actitudes y aspiraciones de los padres y los hijos ante el mundo. Esta dinámica discursiva de contrastes evidencia una visión negativa sobre la sociedad novohispana (e hispana también), que recuerda la tradición de discursos de advertencia y desengaño. Por ejemplo, los parlamentos de Malicia, Engaño y Mentira son un aleccionamiento perverso para el hijo construido mediante la parodia de aquellos discursos admonitorios sobre la vanidad del mundo, pues ensalzan el valor material del dinero y de la vida; precisamente por esta subversión, el tono cómico inicial de la sección cesa pronto en favor de otro amonestante.

La soberbia y cobardía del Engaño (dos rasgos que lo asemejan al miles gloriosus) difiere de la actitud respetuosa, honorable y valiente de Gracilvio, guiado por el consejo paterno y las voces del Cuidado y del Recelo. La despedida entre Tirrreno y su hijo, cuando Gracilvio decide seguir a la 
Virtud para casarse con ella, es una apelación a la pobreza y la sencillez de vida que, por tal razón, facilita la apreciación de lo verdaderamente bueno y santo, es decir, de la Virtud. Es el espectador / lector quien entenderá y aprovechará lo positivo del discurso paternal que procura el bien del hijo en la sociedad -además de la seguridad ofrecida por la familia y los principios y conocimientos adquiridos en la escuela- cuando la vigilancia del padre y del maestro (un segundo padre) ya no están presentes para corregir y reparar; un bien que apreciará mejor el individuo cuando ha de bastarse por sus medios y queda solo con la responsabilidad de sus elecciones y las consecuencias de sus actos.

Por último, la propuesta alegórica de Cigorondo representa los males que acechan al joven antes de alcanzar la madurez, primero, y luego cuando asume las responsabilidades que le exige la sociedad, como el matrimonio y el trabajo. Aunque la obra está inconclusa, los tópicos descritos en las páginas anteriores apuntan a un desarrollo que pondría en peligro el camino de rectitud moral de Gracilvio y, seguramente, la oportuna y definitiva corrección que logra él al desarrollar la cabal conciencia de lo justo y bueno. El impacto de las Églogas, si la obra fue representada, afectaría tanto a los alumnos que participaron en la representación -muchos en la edad de la puericia-como a los espectadores -el resto de los estudiantes, amigos, padres y maestros de los jóvenes actores-; en otras palabras, esta obra estaba dirigida al público del círculo escolar y familiar del colegio jesuita donde se hubiera montado la obra. Quedan varios aspectos por considerar sobre este texto, pero por ahora confiamos en haber ofrecido elementos que ayuden a entender el valor literario de estas inéditas Églogas del Engaño del jesuita novohispano Juan de Cigorondo.

\section{Referencias:}

Alonso, J. (2006). "Tragedia intitulada Oçio" de Juan Cigorondo y Teatro de colegio novohispano del siglo XVI. Ciudad de México: El Colegio de México.

Alonso, J. (Dir.) (2016). Catálogo del antiguo teatro escolar hispánico. Obtenido el 29 de julio del 2017 de Teatresco. Antiguo Teatro Escolar Hispánico, Universitat de València: http://parnaseo.uv.es/Ars/TEATRESCO/BaseDatos/Bases_teatro_Escolar.htm 
Arteaga, A. (2015). Niños y adolescentes en el teatro jesuita novohispano. En R. Olivares Zorrilla (Ed.), Pliegos de semiótica y literatura novohispana (pp. 48-68). Ciudad de México: Grupo Destiempos.

Arteaga, A. (2016). Estudio introductorio. En J. de Cigorondo, Comedia a la gloriosa Magdalena (pp. 11-76). Ciudad de México: Bonilla Artigas Editores.

Arteaga, A. (2017a). Sobre la "Égloga del Santísimo Sacramento". IHS. Antiguos Jesuitas en Iberoamérica, 5 (1), 227-241.

Arteaga, A. (2017b). Sobre el teatro eglógico de Juan de Cigorondo: una revisión. Obtenido el 31 de julio del 2017: https://youtu.be/WaOHzzeB3kE

Cigorondo, J. de (1979). Égloga pastoril al nacimiento del niño Jesús. En O. Arróniz, Teatro de evangelización en Nueva España (pp. 189-238). Ciudad de México: Universidad Nacional Autónoma de México.

Cigorondo, J. de (2012). Colloquio a lo pastoril hecho a la electión del Padre Prouinçial Francisco Baes y a la del Padre Visitador del Pirú, Esteuan Páez, Ciudad de México, 1598. En J. Alonso Asenjo (Ed.), Teatro colegial colonial de jesuitas de México a Chile (pp. 21-120). València: Publicacions de la Universitat de València.

Cigorondo, J. de (2015). Églogas del Engaño. Mss. 17286 de la Biblioteca Nacional de España. Versión paleográfica de Alejandro Arteaga Martínez y Ana Lilia Félix Pichardo, inédito.

Childs, D. (2014). Pirate Nation. Elizabeth I and her Royal Sea Rovers. Seaforth: Barnsley.

Locke, J. C. (2011). Primera parte. Estudio preliminar y criterios de edición. En E. de Salazar, "Qui navigant mare enarrant pericula eius": la Navegación del alma (pp. 17-44). Ciudad de México: El Colegio de México.

Salazar, E. de (2011). "Qui navigant mare enarrant pericula eius": la Navegación del alma. Ciudad de México: El Colegio de México. 
Soldati, B. (1908). Il Collegio Mamertino e le origini del teatro gesuitico, con l'aggiunta di notizie inedite sulla drammatica conventuale messinese nei secoli XVI, XVII, XVIII e con la pubblicazione della "Giuditta" del P. Tuccio. Torino: Ermanno Loescher. 